\title{
Ovulation hormonal imbalance recognition system using saliva's conductivity analysis based on potentiometric method
}

\author{
Romeo Jr. Jorda ${ }^{1}$, Kit Erick Bartolome ${ }^{2}$, Christopher Buban ${ }^{3}$, Ma. Aimee De Los Reyes ${ }^{4}$, \\ Angelo Maingat ${ }^{5}$, Micaela Joyce Oledan ${ }^{6}$, Lean Karlo Tolentino ${ }^{7}$ \\ 1,2,3,4,5,6,7 Electronics Engineering Department, Technological University of the Philippines, Philippines \\ ${ }^{1,7}$ Center for Engineering Design, Fabrication, and Innovation, College of Engineering, Technological University of the \\ Philippines, Philippines
}

\begin{tabular}{|c|c|}
\hline Article Info & ABSTRACT \\
\hline Article history: & \multirow{10}{*}{$\begin{array}{l}\text { Hormonal imbalance is often pointed out by medical experts to be the cause of } \\
\text { menstrual irregularity, a common problem of women. This study aims to } \\
\text { develop a device that would determine if a patient has hormonal imbalance by } \\
\text { testing saliva's conductivity onto the device for } 28 \text { consecutive days, thus, } \\
\text { determining the cause of the patient's menstrual irregularity. To test the } \\
\text { accuracy of the device, the researchers selected three women residing in one } \\
\text { home to use the device. To determine if a woman has hormonal imbalance, the } \\
\text { data, when plotted in a chart, should have a sudden peak. However, data can't } \\
\text { be analyzed through visual assumptions only. Therefore, the data is analyzed } \\
\text { through sample standard deviation. If one data is higher or lower than the sum } \\
\text { and difference of the sample standard deviation and the mean, the woman is } \\
\text { negative in hormonal imbalance. Comparing the result from the device and } \\
\text { from the blood test, it is concluded that the results from the device matched } \\
\text { the results from the blood test and medical expert interpretation. }\end{array}$} \\
\hline Received Jan 15, 2019 & \\
\hline Revised Apr 27, 2019 & \\
\hline Accepted May 5, 2019 & \\
\hline Keywords: & \\
\hline Hormonal imbalance & \\
\hline Menstruation & \\
\hline Ovulation & \\
\hline Potentiometric method & \\
\hline Saliva conductivity & \\
\hline
\end{tabular}

Copyright () 2019 Institute of Advanced Engineering and Science. All rights reserved.

\section{Corresponding Author:}

Romeo Jr. Jorda

Electronics Engineering Department,

Technological University of the Philippines,

Ayala Boulevard, Ermita, Manila, Philippines.

Email: romeo_jorda@tup.edu.ph

\section{INTRODUCTION}

Women who are living in the rural areas do not usually have access to medical attention through a doctor and access to medical diagnostic devices [1, 2]. Anemia [3], diabetes [4], and irregular menstrual cycle are some of the problems that women encounter in the rural areas since time immemorial. The focus of this paper which is irregular menstrual cycle is caused by numerous reasons, including, but not limited to pregnancy, breastfeeding, extreme weight loss, eating disorders, excessive exercising, stress, and various medical conditions in need of treatment [5-7].

Different tests can be possibly undergone by women to see if there are irregularities in their menstrual cycle, and that is by determining if a woman has hormonal imbalance or not through blood tests, saliva tests, urine tests, and pelvic ultrasound [8]. Saliva test is one of some of the non-invasive methods of ovulation predictor. Previous studies showed that, before ovulation, there is an abrupt decrease in the saliva conductivity which is due to estrogen increase and saliva electrolyte concentration decrease [9, 10].

Saliva tests can be implemented using biosensors. A biosensor is a component that measures a parameter, distinguishes a substance (analyte), and transmits this information to a processor or microcontroller for analysis [11-17]. Normally, electrolyte solution and mucus, which are the input analytes of the saliva, are 
sensed by saliva biosensors made of electrolyte-insulator-semiconductor (EIS) and polymer/piezoelectric, respectively [15].

The focus of this study is to develop a device capable of recognizing a female's menstrual irregularity by determining the conductivity of the saliva sample, one of the most convenient specimens to acquire, within 28 consecutive days. The data extracted throughout the 28-day testing will be analyzed using mean and standard deviation. The developed device will generate a report if the female is positive in hormonal imbalance or not.

\section{RESEARCH METHOD}

\subsection{Research design}

The research design used in the study is semi- experimental since the proponents do field tests to obtain results. The inputs, processes and outputs of the study are identified in Figure 1. It is shown that the input of the device will be saliva sample obtained from a patient. The conductivity of the saliva sample will then be measured by the device. The processor will interpret the data and show the results on a display.

The saliva input will undergo a process that is shown in Figure 2. The study focuses on the conductivity level of saliva samples. The conductivity tester is intended to apply an electrical current to the saliva sample to measure its conductivity. The researchers used an Arduino UNO as the microcontroller for the system to analyze the data from the conductivity sensor. The software used is Arduino C programming language to process the data gathered from the saliva sample for a period of 28 consecutive days. The results from the microcontroller's interpretation will then be presented on the TFT LCD. The process to detect hormonal imbalance from saliva samples is shown in Figure 3.

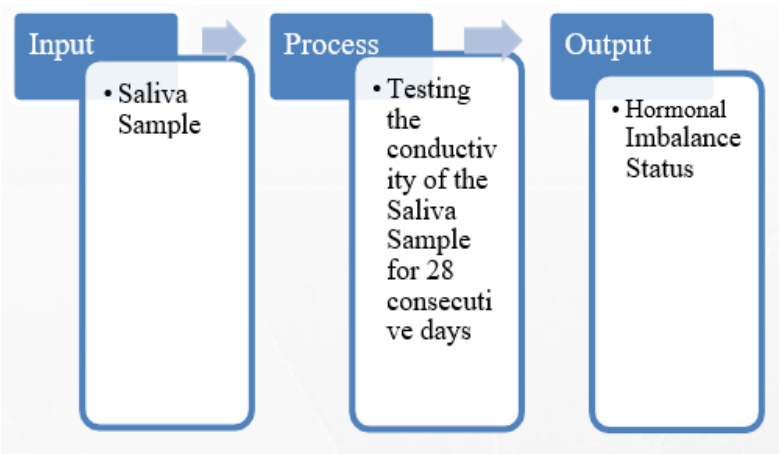

Figure 1. Process flowchart

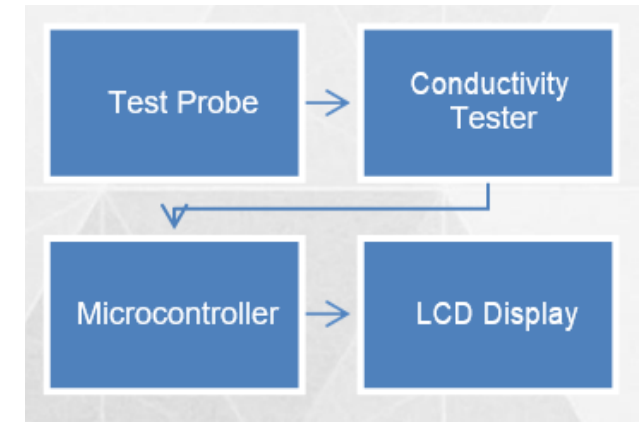

Figure 2. Block diagram

\subsection{Hardware development}

The sensor of the device shown in Figure 4 will be the key to measure the electrolytes of the saliva sample that will then measure its conductivity. This sensor has a USB plug that will be connected to the main device. The sensor will send the needed data to the Arduino UNO.

The Arduino UNO shown in Figure 4 serves as the microcontroller for the system. It will analyze the data from the conductivity sensor. Afterwards, the microcontroller will interpret the data according to its proportionality with the hormonal levels. The result from the microcontroller's interpretation will then be presented on the LCD Display. The LCD display shown in figure 6 is where the graph of the recorded data result from the Arduino UNO will show.

\subsection{Software Development}

The Arduino UNO is programmed not only to supply the circuits and the output but also to process the data of the conductivity tester. As the conductivity tester detects the saliva sample through applying an electrical current, the Arduino UNO analyzes and interprets data. The result will be presented on the LCD Display and shall be restored on the Arduino UNO's system. The user/s has the option of interpreting the recorded data or complete the 28-day menstrual cycle record. The final output is to identify hormonal imbalance. 


\section{i. Profile page}

In doing the interface of the device, Arduino-C programming language is used. The LCD will show the profile page of the device wherein you can select where you want to save your data. The device can save up to three (3) profiles only at the same time.

ii. Test page

The LCD will show the interface shown in Figure 8 as the Test Page of the device. This will show the page where you can start measuring your hormonal level for the day.

\section{iii. Chart page}

The LCD will also show the interface shown in Figure 9 as the chart page of the device. In the result page, the level of hormones is indicated by a bar graph including the number of days you are testing your hormonal level.

\section{iv. Result page}

The LCD will show the interface shown in Figure 10 as the result page of the device. In this page, hormonal imbalance will be detected by the daily measurement of your hormonal level. It will be "Positive" or "Negative" and "Insufficient Data" if the number of the saved data from your measurement/s is not enough to say if you have a hormonal imbalance or not.

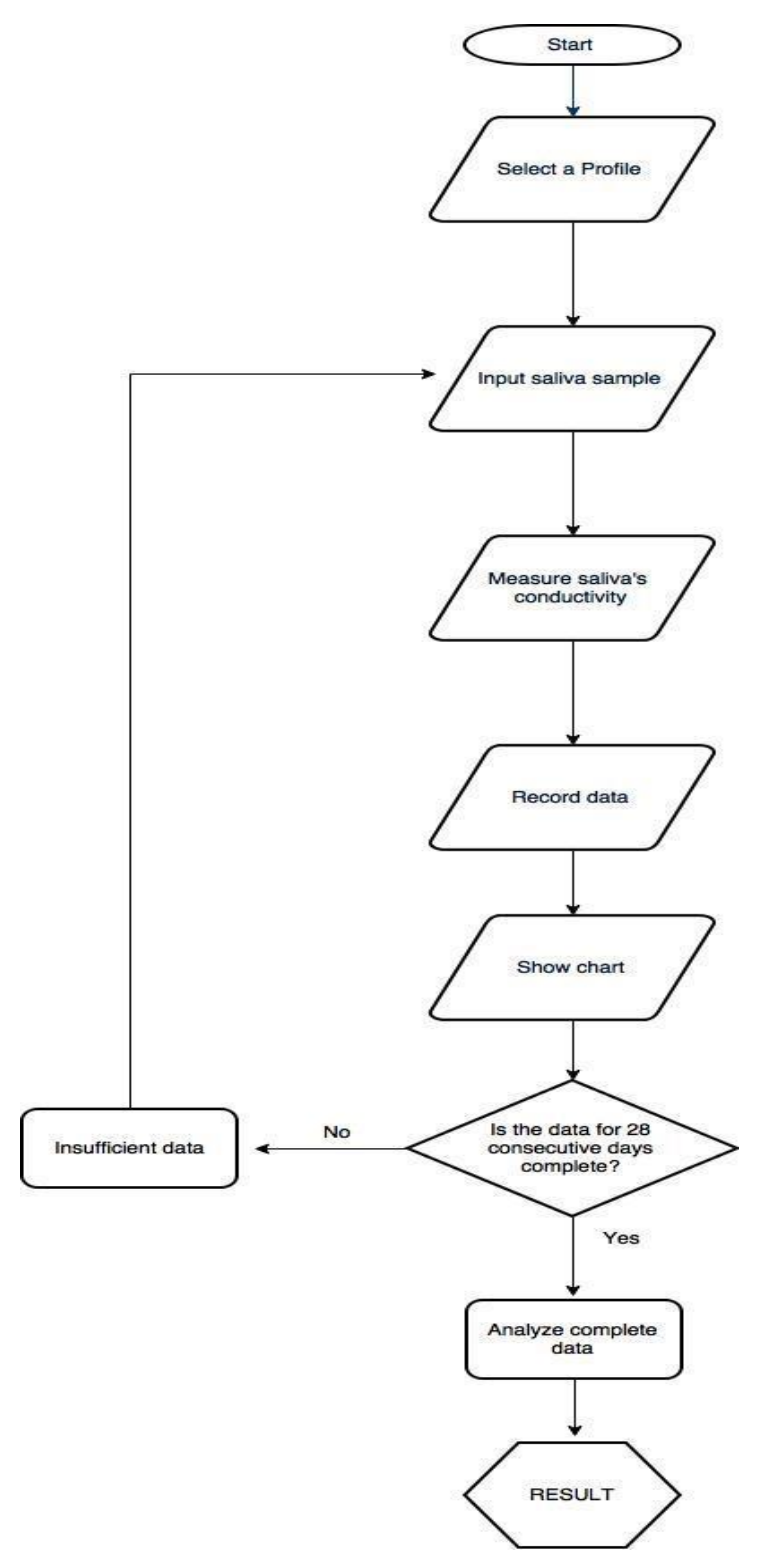

Figure 3. System flowchart 


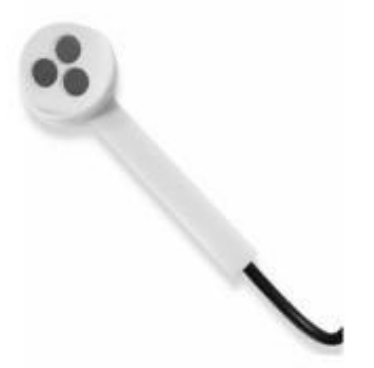

Figure 4. Oral sensor

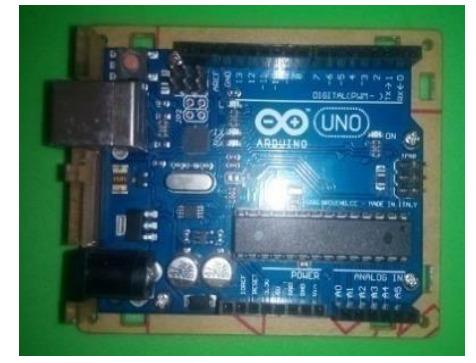

Figure 5. Arduino UNO

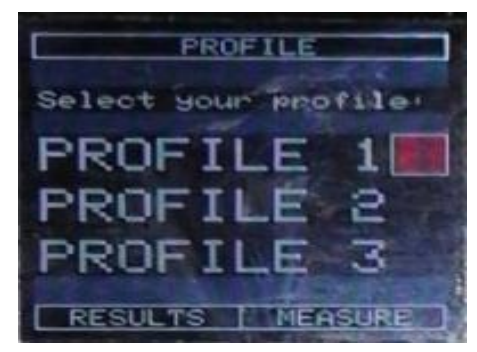

Figure 7. Profile page

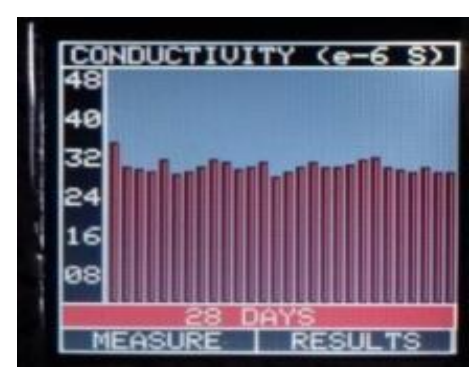

Figure 9. Chart page

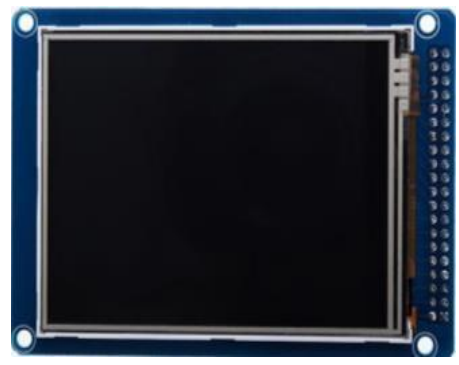

Figure 6. TFT LCD display

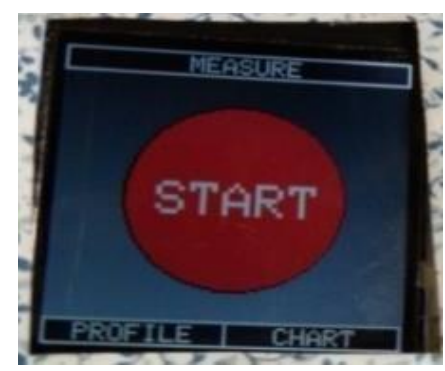

Figure 8. Test page

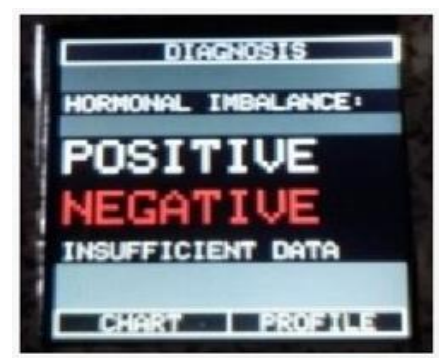

Figure 10. Chart page

\section{RESULTS AND DISCUSSION}

To test the accuracy and effectiveness of the device, 3 females from one family residing in one home to undergo testing saliva sample for 28 consecutive days. Table 1 shows the data of the 3 women who tested the device. To determine if a woman is POSITIVE or NEGATIVE in hormonal imbalance, the data when plotted in a chart should have a sudden peak. The 3 consecutive Figures (Figures 11-13) shows the data of the three subjects when plotted. 


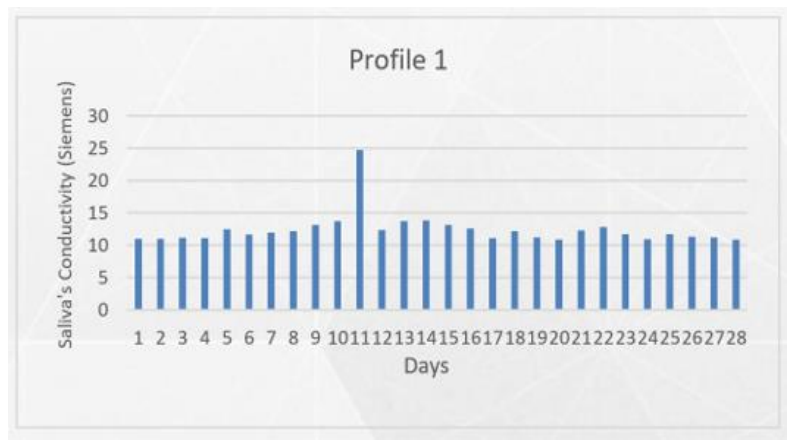

Figure 11. Profile for Female 1

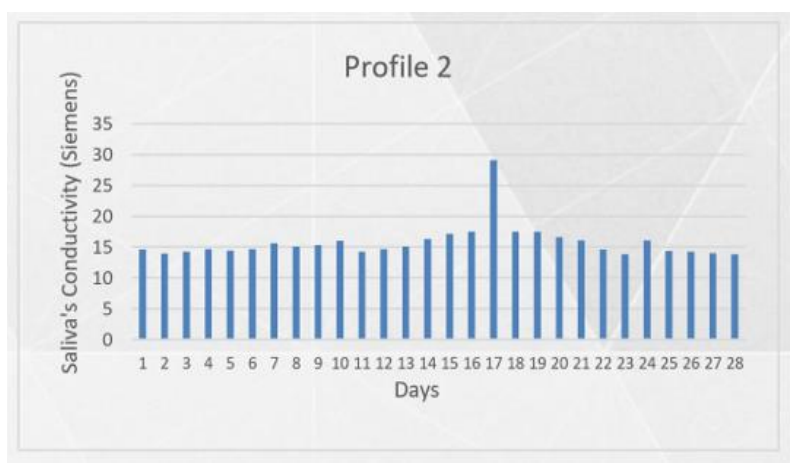

Figure 12. Profile for Female 2

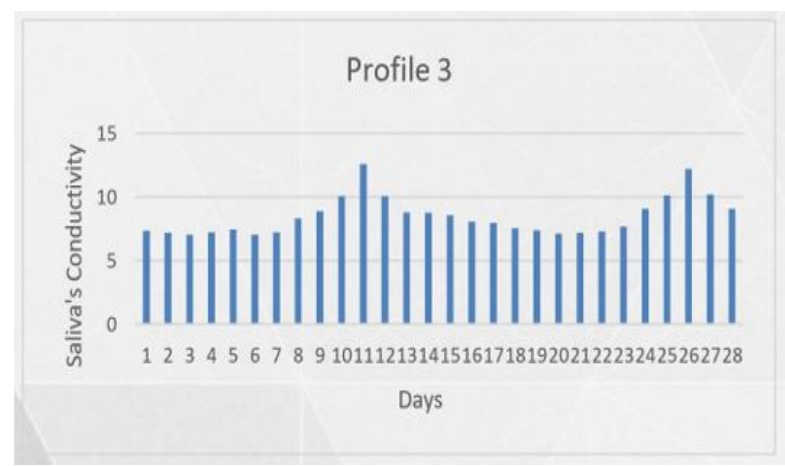

Figure 13. Profile for Female 3

Table 1. Saliva's conductivity of the 3 Females in 28 days

\begin{tabular}{cccc}
\hline Day & Female 1 & Conductivity (microSiemens) & \\
& 10.96106629 & Female 2 & Female 3 \\
\hline 1 & 10.9502639 & 14.63871648 & 7.362035 \\
3 & 11.17031377 & 13.95245005 & 7.198232 \\
4 & 11.08229714 & 14.23649968 & 7.030717 \\
5 & 12.43394467 & 14.65545036 & 7.234215 \\
6 & 11.64225674 & 14.42126389 & 7.449788 \\
7 & 11.9541439 & 14.67803725 & 7.030767 \\
8 & 12.15923737 & 15.5950283 & 7.234058 \\
9 & 13.16794396 & 15.09616256 & 8.317253 \\
10 & 13.71629221 & 15.31346666 & 8.886835 \\
11 & 24.73777954 & 16.04827321 & 10.05814 \\
12 & 12.35727349 & 14.23649668 & 12.59049 \\
13 & 13.73928336 & 14.65609474 & 10.07739 \\
& & 15.08022681 & 8.781636
\end{tabular}




\begin{tabular}{cccc}
\hline Day & \multicolumn{3}{c}{ Conductivity (microSiemens) } \\
& Female 1 & Female 2 & Female 3 \\
\hline 14 & 13.80387605 & 16.32972991 & 8.752582 \\
15 & 13.15391395 & 17.14589442 & 8.581923 \\
16 & 12.5906527 & 17.50332563 & 8.04816 \\
17 & 11.1206527 & 29.1188632 & 7.972956 \\
18 & 12.15775908 & 17.47274252 & 7.561322 \\
19 & 11.22044814 & 17.47304782 & 7.395739 \\
20 & 10.84198885 & 16.6325699 & 7.121239 \\
21 & 12.28154207 & 16.06890346 & 7.182257 \\
22 & 12.82906553 & 14.59364009 & 7.281995 \\
23 & 11.74770626 & 13.84447121 & 7.677838 \\
24 & 10.93816654 & 16.09709769 & 9.070706 \\
25 & 11.73240726 & 14.3893602 & 10.13767 \\
26 & 11.30927474 & 14.23852375 & 12.20658 \\
27 & 11.2064908 & 14.02681928 & 10.19867 \\
28 & 10.87890689 & 13.8264777 & 9.071776 \\
\hline
\end{tabular}

To determine if the result is POSITIVE or NEGATIVE in hormonal imbalance, the sum and difference of the sample standard deviation and the mean shall be compared to every data gathered in 28 consecutive days. Table 2 shows the mean and standard deviation of the three profiles. Each profile has its own range to determine if the subject is positive or negative in hormonal imbalance.

Table 2. Using standard deviation to determine hormonal imbalance

\begin{tabular}{cccc}
\hline & \multicolumn{3}{c}{ Subjects } \\
& Female 1 $(\mathrm{F} 1)$ & Female 2 $(\mathrm{F} 2)$ & Female 3 $(\mathrm{F} 3)$ \\
\hline Mean & 12.42542574 & 15.76336451 & 8.482606036 \\
Sample Standard Deviation (S) & 2.588248892 & 2.869483718 & 1.514441596 \\
Mean + S & 15.01367463 & 18.63284823 & 9.997047632 \\
Mean - S & 9.837176848 & 12.89388079 & 6.96816444 \\
\hline
\end{tabular}

Table 3 shows the comparing of data to the computed sum and difference of sample standard deviation and mean. If one data is higher or lower than the sum and difference of the sample standard deviation and the mean, the female is NEGATIVE in hormonal imbalance. However, if two or more data is higher or lower than the sum and difference of the sample standard deviation and the mean, the female is POSITIVE in hormonal imbalance. Note that in Table 3, D means if the value is between the computed (Mean $+S$ ) and $($ Mean $+S), Y$ means Yes, and $\mathrm{N}$ means No.

To check the accuracy of the device, the 3 females underwent Fertility / Hormonal Panel blood testing in a testing clinic. The results of the blood test were interpreted by an Obstetrician and Gynecologist. After gathering the result from the device and the medical expert, Table 4 shows that the result from the device matches with the result from the blood test.

Table 3. Using standard deviation to determine hormonal imbalance

\begin{tabular}{lllllll}
\hline Day & F1 & D & F2 & D & F3 & D \\
\hline 1 & 10.9610 & Y & 14.6387 & $\mathrm{Y}$ & 7.3620 & $\mathrm{Y}$ \\
2 & 10.9502 & $\mathrm{Y}$ & 13.9524 & $\mathrm{Y}$ & 7.1982 & $\mathrm{Y}$ \\
3 & 11.1703 & $\mathrm{Y}$ & 14.2364 & $\mathrm{Y}$ & 7.030 & $\mathrm{Y}$ \\
4 & 11.0822 & $\mathrm{Y}$ & 14.6554 & $\mathrm{Y}$ & 7.2342 & $\mathrm{Y}$ \\
5 & 12.4339 & $\mathrm{Y}$ & 14.4312 & $\mathrm{Y}$ & 7.4497 & $\mathrm{Y}$ \\
6 & 11.6422 & $\mathrm{Y}$ & 14.6780 & $\mathrm{Y}$ & 7.0307 & $\mathrm{Y}$ \\
7 & 11.9541 & $\mathrm{Y}$ & 15.5950 & $\mathrm{Y}$ & 7.2340 & $\mathrm{Y}$ \\
8 & 12.1592 & $\mathrm{Y}$ & 15.0961 & $\mathrm{Y}$ & 8.3172 & $\mathrm{Y}$ \\
9 & 13.1679 & $\mathrm{Y}$ & 15.3134 & $\mathrm{Y}$ & 8.8868 & $\mathrm{Y}$ \\
10 & 13.7162 & $\mathrm{Y}$ & 16.0482 & $\mathrm{Y}$ & 10.058 & $\mathrm{~N}$ \\
11 & 24.7377 & $\mathrm{~N}$ & 14.2364 & $\mathrm{Y}$ & 12.5904 & $\mathrm{~N}$ \\
12 & 12.3572 & $\mathrm{Y}$ & 14.6560 & $\mathrm{Y}$ & 10.0773 & $\mathrm{~N}$ \\
13 & 13.7392 & $\mathrm{Y}$ & 15.0802 & $\mathrm{Y}$ & 8.7816 & $\mathrm{Y}$ \\
14 & 13.8308 & $\mathrm{Y}$ & 16.3297 & $\mathrm{Y}$ & 8.7525 & $\mathrm{Y}$ \\
15 & 13.1539 & $\mathrm{Y}$ & 17.1458 & $\mathrm{Y}$ & 8.5819 & $\mathrm{Y}$ \\
16 & 12.5906 & $\mathrm{Y}$ & 17.5033 & $\mathrm{Y}$ & 8.0481 & $\mathrm{Y}$ \\
17 & 11.1206 & $\mathrm{Y}$ & 29.1188 & $\mathrm{~N}$ & 7.9729 & $\mathrm{Y}$ \\
18 & 12.1577 & $\mathrm{Y}$ & 17.4727 & $\mathrm{Y}$ & 7.5613 & $\mathrm{Y}$ \\
19 & 11.2204 & $\mathrm{Y}$ & 17.4730 & $\mathrm{Y}$ & 7.3957 & $\mathrm{Y}$ \\
20 & 10.8419 & $\mathrm{Y}$ & 16.6325 & $\mathrm{Y}$ & 7.1212 & $\mathrm{Y}$
\end{tabular}




\begin{tabular}{lllllll}
\hline Day & F1 & D & F2 & D & F3 & D \\
\hline 21 & 12.2815 & Y & 16.0689 & Y & 7.1822 & Y \\
22 & 12.8290 & Y & 14.5936 & Y & 7.2819 & Y \\
23 & 11.7477 & Y & 13.8444 & Y & 7.6778 & Y \\
24 & 10.9381 & Y & 16.0970 & Y & 9.0707 & Y \\
25 & 11.7324 & Y & 14.38393 & Y & 10.1376 & N \\
26 & 11.3092 & Y & 14.2385 & Y & 12.2065 & N \\
27 & 11.2064 & Y & 14.0268 & Y & 10.1986 & N \\
28 & 10.8789 & Y & 13.8264 & Y & 9.0717 & Y \\
\hline
\end{tabular}

Table 4. Comparison of hormonal imbalance results

\begin{tabular}{ccc}
\hline Female & Device Results & Medical Expert Results \\
\hline 1 & Negative & Negative \\
3 & Negative & Negative \\
& Positive & Positive \\
\hline
\end{tabular}

\section{CONCLUSION}

The hormonal imbalance detector identifies if a woman has hormonal imbalance through testing saliva sample for 28 consecutive days. The sensor measures the conductance of the saliva sample which is analyzed by the microcontroller in the Arduino UNO. When a woman approaches her ovulation period, her hormonal levels are higher than those of the rest of the menstrual cycle. The researches based the analysis of data from this concept. Computing the sample standard deviation from the data obtained in 28 days can determined how many data had a sudden increase, thus, resulting to determining if the user is NEGATIVE or POSITIVE in hormonal imbalance.

The device's accuracy and effectivity were tested through selecting 3 women to use the device for 28 consecutive days. The 3 women had also undergone blood testing and check - ups with an Obstetrician and Gynecologist before and after the testing. Comparing the result from the device and from the blood test, it is concluded that the results from the device matched the results from the blood test and medical expert interpretation.

\section{ACKNOWLEDGEMENTS}

This study is supported by the University Research and Development Services Office and the University Research and Extension Council of the Technological University of the Philippines. The University is highly acknowledged for the financial support. The authors would like to thank Dr. Elisa Tiu and Dr. Feliza Cortez for their support and cooperation in doing this project, and to our colleagues and professors from the Electronics Engineering Department for the encouragement.

\section{REFERENCES}

[1] A. Andre, "Medical Information System Services and Patient Queue Management to Enhance Services Quality in Indonesia," International Journal of Electrical and Computer Engineering (IJECE), vol. 9, no. 3, 2019.

[2] R. Goins, et al., "Perceived barriers to health care access among rural older adults: a qualitative study," The Journal of Rural Health, vol. 21, no. 3, pp. 206-213, 2005.

[3] H. A. Aliyu, et al., "Normal and abnormal red blood cell recognition using image processing," Indonesian Journal of Electrical Engineering and Computer Science, vol. 14, no. 1, pp. 100-104, 2019.

[4] D. Devaraj, et al., "Development of a hybrid framework to characterize red lesions for early detection of diabetic retinopathy," Indonesian Journal of Electrical Engineering and Computer Science, vol. 13, no. 3, pp. 962-973, 2019.

[5] V.B. Popat, et al., "The menstrual cycle," Annals of the New York Academy of Sciences, vol. 1135, no. 1, pp. 43-51, 2008.

[6] L.M. Nelson, "Primary ovarian insufficiency," New England Journal of Medicine, vol. 360, no. 6, pp. 606-614, 2009.

[7] P. Smith, "A comprehensive look at hormones and the effects of hormone replacement," in 14th Annual International Congress on Anti-Aging Medicine, Orlando, Florida, USA, 2005.

[8] H.W. Su, et al., "Detection of ovulation, a review of currently available methods," Bioengineering \& translational medicine, vol. 2, no. 3, pp. 238-246, 2017.

[9] J. E. Mink, et al., "Energy harvesting from organic liquids in micro-sized microbial fuel cells," NPG Asia Materials, vol. 6 , no. 3, p. e89, 2014.

[10] Z. Huang, et al., "Ovulation prediction by monitoring the conductivity of woman's saliva," Proceedings of the 19th Annual International Conference of the IEEE Engineering in Medicine and Biology Society, vol. 5, pp. 2344-2346, 1997. 
[11] M. Aljanabi, "Resonance frequency analysis of laser optical fiber based on microcantilever," International Journal of Electrical \& Computer Engineering (IJECE), vol. 9, no. 4, pp. 3090-3099, 2019.

[12] A.M. Dinar, et al., "Comprehensive identification of sensitive and stable ISFET sensing layer high-k gate based on ISFET/electrolyte models," International Journal of Electrical \& Computer Engineering (IJECE), vol. 9, no. 2, pp. 926-933, 2019.

[13] A.N. Nordin, et al., "Content Cytotoxicity Studies of Colorectal Carcinoma Cells Using Printed Impedance Sensors," Bulletin of Electrical Engineering and Informatics, vol. 6, no. 4, pp. 317-326, 2017.

[14] E. Galido, et al., "EMG Speed-Controlled Rehabilitation Treadmill With Physiological Data Acquisition System Using BITalino Kit," 2018 IEEE 10th International Conference on Humanoid, Nanotechnology, Information Technology, Communication and Control, Environment and Management (HNICEM), pp. 1-5, 2018.

[15] R.T.M. Cruz, et al., "IoT-based monitoring model for pre-cognitive impairment using pH level as analyte," International Journal of Engineering Research and Technology, vol. 12, no. 5, pp. 711-718, 2019.

[16] T. Adam, et al., "Semiconductor Nanowires Biosensors for Highly Selective and Multiplexed Detection of Biomolecules," Journal of Telecommunication, Electronic and Computer Engineering (JTEC), vol. 10, no. 2-8, pp.155-158, 2018.

[17] R.D.A.A. Rajapaksha, et al., "High-performance Electrical Variable Resistor Sensor for E. coli O157: H7 Detection," Journal of Telecommunication, Electronic and Computer Engineering (JTEC), vol. 10, no. 1-17, pp. 61-64, 2018. 